\title{
Vontade de ser máquina: imaginação material em o apocalipse dos trabalhadores
}

\author{
The will to be a machine: material imagination in o apocalipse dos trabalhadores
}

\author{
Bruno Mazolini de Barros \\ Luara Pinto Minuzzi \\ Pontifícia Universidade Católica do Rio Grande do Sul - Porto Alegre - Rio Grande do Sul - Brasil
}

$\diamond$

\begin{abstract}
Resumo: Neste artigo, pretendemos analisar o romance o apocalipse dos trabalhadores, do escritor português Valter Hugo Mãe, a partir dos estudos do filósofo Gaston Bachelard sobre a imaginação material. Para isso, o personagem Andriy foi selecionado como foco do estudo: ucraniano, o homem vive uma realidade dura de imigrado em Portugal, trabalhando muito e ganhando pouco, em um sistema exemplar de capitalismo tardio, longe da família e sem amigos. Por isso, ele decide virar máquina e se despir de sua humanidade para não sentir mais - e esse processo de metalização ganha novos significados quando interpretado principalmente à luz da simbologia do elemento terrestre examinado por Bachelard em $A$ terra e os devaneios da vontade.
\end{abstract}

Palavras-chave: Valter Hugo Mãe; o apocalipse dos trabalhadores; Gaston Bachelard; Imaginação material

\begin{abstract}
This study aims to analyze the novel o apocalipse dos trabalhadores, of the Portuguese writer Valter Hugo Mãe, according with the theory of the philosopher Gaston Bachelar about the "material imagination". To do this, the analyze will be focused on the character Andriy: Ukrainian, he has a hard life as immigrant in Portugal, working a lot and not getting much from it, in a late capitalism system, far from his family and without friends. Because of this, he decides to become a machine, giving away his own humanity condition: this process of turning himself a metal structure revels subtle meanings when interpreted mainly with the symbolic aspect of the earth element, exanimated by Barchelard in La terre et les rêveries de la volonté. Keywords: Valter Hugo Mãe; o apocalipse dos trabalhadores; Gaston Bachelard; Material imagination
\end{abstract}

O sentimento de medo, de solidão e de pertença são elementos recorrentes nos romances de Valter Hugo Mãe, ${ }^{1}$ como em o remorso de baltazar serapião, o filho de mil homens e a maquina de fazer espanhóis. Essas experiências estão presentes também em o apocalipse dos trabalhadores, romance no qual tais questões estão significativamente calcadas em o que Gaston Bachelard entende por imaginação material.

A fim de compreender melhor como o livro de Mãe relaciona-se com o conceito de imaginação material de Bachelard (2013a), é necessário, primeiramente, entender

\footnotetext{
$1 \mathrm{O}$ autor agora assina com iniciais maiúsculas, mas os romances citados neste trabalho são do período em que grafava tudo em minúsculas, inclusive nomes próprios como os das personagens e topônimos. Nas citações diretas, eles aparecerão de acordo com a escolha do romancista.
}

de onde o teórico partiu para criar tal ideia e como ele a estrutura e a caracteriza. Em a Água e os sonhos, ele afirma acreditar que é possível estabelecer uma espécie de lei dos quatro elementos no reino da imaginação - e isso seria chamado por ele de imaginação material. O filósofo francês compreende a imaginação como a "faculdade de formar imagens que ultrapassam a realidade, que cantam a realidade" (2013a, p. 18 - grifo do autor). Ou seja, não é meramente criar imagens da realidade: na verdade, o imaginário e a imaginação consistiriam na capacidade do ser humano de deformá-las, visto que, caso elas continuem como imagens tradicionais, não haverá imaginação nem ação imaginante, e a imagem será simplesmente algo de presente que não nos faz pensar em uma outra imagem ausente. O perigo disso reside no fato de uma imagem 
estável, acabada, "[...] cortar as asas à imaginação" (BACHELARD, 2001, p. 2).

Além disso, Bachelard ressalta a importância da função da imaginação, mesmo que seja constante a negligência, o desprezo em relação às "provas oníricas". Isso ocorre pois, como o estudioso explica, raramente os fenômenos que atingem os limites da credulidade são tema e objeto de estudos. As experiências diurnas são consideradas verdadeiramente sérias, enquanto que as noturnas, resultados dos sonhos e da imaginação, não são sequer consideradas: "subestima-se o que é oniricamente possível sem ser realmente possível. [...] Para eles (os realistas) a vida noturna é sempre um resíduo, uma seqüela da vida acordada" (BACHELARD, 1990, p. 101). De acordo com Bachelard, em oposição a essa difundida crença, "a imaginação inventa mais que coisas e dramas; inventa vida nova, inventa mente nova; abre olhos que têm novos tipos de visão" (BACHELARD, 2013a, p. 18). Portanto, o imaginário é capaz de desestabilizar o homem, de tirá-lo de sua vida comum, ordinária e de apresentá-lo a realidades mais ricas. Consequentemente, tem o poder de fazer com que o homem se sinta rejuvenescer "[...] ao nos restituir ininterruptamente a faculdade de nos maravilharmos"(BACHELARD, 2013a, p. 18). Se estudar a imaginação material permite perceber, por exemplo, que os sonhos, e também os devaneios, "são sobretudo uma vida imitada da matéria, uma vida fortemente enraizada nos elementos materiais" (BACHELARD, 2013a, p. 135, grifo do autor), os quatro elementos são igualmente relevantes para a capacidade do homem de se descolar da sua realidade e de inventar mundos novos.

A partir desse pensamento, Bachelard organiza as imagens a partir do que ele chama de "lei dos quatro elementos" (BACHELARD, 2013a, p.4), aquelas matérias que, segundo o autor, são fundamentais: água, fogo, terra e ar. O teórico as caracteriza dessa forma, como fundamentais, visto que ele percebeu ser justamente o fato de as filosofias primitivas associarem-se a um determinado elemento o motivo de essas escolas e sistemas de crenças ainda conquistarem muitos seguidores e fiéis até hoje. Em relação a esse assunto, o filósofo é categórico: "na ordem da filosofia, só se persuade bem sugerindo devaneios fundamentais, restituindo aos pensamentos sua avenida de sonhos" (ibidem, p.4). Muito mais do que matérias, a água, o fogo, a terra e o ar configuram-se, cada um, como um "sentimento humano primitivo", "uma realidade orgânica primordial" e "um temperamento onírico fundamental" (ibidem, p.5), e os sonhos e a imaginação dependem obrigatoriamente desses quatro elementos. É apenas quando conectadas com uma dessas matérias que as imagens enriquecem-se e ganham novas significações, ao se relacionarem, consequentemente, com o cosmos (WUNENBURGER, 2003). Dessa forma, um produto do imaginário apenas será consistente caso apresente um dos elementos como principal:

Para que um devaneio tenha prosseguimento com bastante constância para resultar em uma obra escrita, para que não seja simplesmente a disponibilidade de uma hora fugaz, é preciso que ele encontre sua matéria, é preciso que um elemento material lhe dê sua própria substância, sua própria regra, sua poética específica (BACHELARD, 2013a, p.4).

Entretanto, é curioso perceber que, apesar de serem quatro os elementos, Bachelard dedicou cinco volumes a esse estudo: se a água, o ar e o fogo foram contemplados com um livro cada ( $A$ água e os sonhos, A psicanálise do fogo e $O$ ar e os sonhos), a terra é tema de duas obras: $A$ Terra e os devaneios da vontade e $A$ terra e os devaneios do repouso. Dessa forma, concluímos, com o antropólogo Gilbert Durand, discípulo do filósofo francês, que Bachelard percebeu acertadamente que uma classificação demasiada cartesiana e exata, racional e objetiva, não conseguiria acomodar os "caprichos da louca da casa" (DURAND, 2002, p. 35), da imaginação que não funciona a partir de uma lógica linear. Se, no primeiro tomo dedicado ao elemento terrestre, Bachelard discorre sobre o aspecto mais agressivo da terra e cita as matérias duras, as ferramentas, os rochedos e cristais ligados à ação e à vontade do homem, no segundo, ele abarca questões como o psiquismo involutivo, o enraizamento, a afetividade. A casa natal e onírica, o labirinto, a serpente, etc., são elementos trazidos como exemplos da forma com que a terra funciona através de uma atitude de repouso. Assim, a dicotomia dessa matéria fica bastante evidente.

Porém, apesar de apenas à terra terem sido dedicados dois livros, os demais elementos são igualmente marcados pela polaridade. Tal característica, na verdade, é fundamental para que um elemento possa ser considerado uma matéria original e consiga desenvolver o seu papel psicológico, envolvendo a alma inteira do homem que sonha: "não há devaneio sem ambivalência, não há ambivalência sem devaneio" (BACHELARD, 2013a, p. 109). Essa dialética, por sua vez, é capital para o equilíbrio da humanidade, uma vez que "[...] esta amplificação interna da consciência sonhadora proíbelhe [ao homem] tanto a alienação quanto o solipsismo" (DURAND, 1993, p. 68). Bachelard (2013a) afirma que cada elemento apresenta dois lados, dois aspectos: um deles relaciona-se com o Animus, aquele polo masculino, relacionado à luta e à vontade, e o outro com a Anima, o feminino, conectado com a reconciliação e com a paz. Desse modo, mesmo que aos elementos aquático, ígneo e aéreo não tenham sido dedicadas duas obras, apenas com a observação do sumário dos livros, o leitor já percebe a contradição fundamental dessas matérias: as águas 
podem ser claras, amorosas, maternais, purificadoras ou profundas, mortas, pesadas e violentas; o ar pode relacionar-se tanto com o voo, quanto com a queda; o fogo, por fim, indica purificação e idealização, mas também sexualidade.

Além dessa ambivalência própria de cada matéria, dois elementos, a cada vez, ainda podem ser misturados: o álcool e as águas termais, por exemplo, derivam da combinação entre fogo e água; já a massa origina-se da mistura da água e da terra. Mais do que um simples costume, o fato de a imaginação material trabalhar com a ideia de composição e de combinação coloca-se como uma necessidade, visto que tal imaginação, mesmo que eleja um dos elementos como favorito, igualmente quer "[...] guardar a variedade do universo" (BACHELARD, 2013a, p.97) em cada imagem.

Durand ainda ressalta o fato de Bachelard não limitar sua cosmologia simbólica a uma mera união entre o quente e o frio, o seco e o úmido, sensações cuja origem encontra-se em cada um dos elementos primordiais. O teórico não apenas considera essas sensações, mas igualmente muitas outras resultantes da relação entre as quatro principais: o claro e o escuro, o alto e o baixo, o pesado e o leve, etc. (DURAND, 1993). Na verdade, sensação é uma palavra-chave para o pensamento e a teoria de Bachelard, como salienta Durand: "a água, a terra, o fogo e o ar, e todos os seus derivados poéticos não são mais do que o lugar mais comum deste império em que o imaginário vem prender-se directamente à sensação" (DURAND, 1993, p. 65).

A partir da teorização e da classificação das imagens a partir dos quatro elementos fundamentais, podemos pensar sobre o romance o apocalipse dos trabalhadores, e, em especial, sobre o caso do personagem ucraniano Andriy. Emigrado da Ucrânia em busca de uma vida melhor, Andriy deixa a família para tornar-se um operário da construção civil em Portugal. A vida em Lisboa é muito austera para o jovem de 23 anos, que resolve adotar uma postura consciente - e devaneante - em relação à sua condição de trabalhador imigrante. Os estudos de Bachelard em A terra e os devaneios da vontade são essenciais para entender esse processo do ucraniano:

Tal será, portanto, para nós, a matéria: a intimidade da energia do trabalhador. Os objetos da terra nos devolvem o eco de nossa promessa de energia. O trabalho da matéria, assim que lhe devolvemos todo o seu onirismo, desperta em nós um narcisismo de nossa coragem (2013b, p. 7 - grifos nossos).

Andriy decide, deliberadamente, tornar-se uma máquina, e endurecer-se, trabalhando. Na verdade, ele pertence a um grupo de homens caracterizados como duros e resistentes, os imigrantes do leste europeu. Como explica um personagem português do romance, esses imigrantes estão "[...] dispostos a carregar com os camiões aos ombros para sobreviverem. os do leste [...] são uns resistentes" (MÃE, 2013, p. 15)2. Esse aspecto de resistência já é considerado natural entre seus semelhantes; contudo, isso é potencializado em Andriy quando ele migra para Portugal.

O narrador indica que "sua mãe via partir o filho como se entrasse pela terra adentro" (p.39), como se adentrasse em uma mina - elemento que, de acordo com Bachelard (2008), é uma "planta coberta de terra" (BACHELARD, 2013b, p. 195), extremamente fértil: se uma mina se esgota, basta cobri-la com terra para que, passadas algumas décadas, ela esteja novamente em pleno crescimento. Andriy, portanto, vai para baixo do elemento terrestre a fim de se incorporar à mina no subsolo e de se transformar em metal. Isso surge com bastante clareza no trecho a seguir, longo, mas importante porque traz a gênese do processo:

o andriy não estava com vontade de ouvir nada. Ficava masculino, calado de chumbo a querer empedernir para secar todos os sentimentos. se pudesse, esquecia-se de ser emotivo, gostava de acreditar que a vida podia existir apenas como para uma máquina de trabalho perfeita, incumbida de uma tarefa muito definida, com erro reduzido e já previsto, e com isso atender ao mais certeiro objectivo, enviar algum dinheiro para a família na ucrânia, e nem pensar muito nisso e nunca dramatizar a questão. depositar o dinheiro, saber que seria levantado lá tão longe, e mais nada, pensar no acro como um ofício a mais, um item nos seus afazeres. retirar daí a felicidade das máquinas, uma espécie de contínuo funcionamento sem grandes avarias ou interrupções. a felicidade das máquinas, para não sentir senão através do alcance constante de cada meta, sempre tão definida e cumprida quanto seria de esperar de si. as botas suspendiam-se e ele começara a balançá-as muito lentamente, como a criar um embalo, e talvez pudesse chorar. o mikhalkov estaria em casa em muito pouco tempo, assim como os outros, e ficar para ali a chorar seria deitar por terra a regra mais básica da sobrevivência e progressiva metamorfose para máquina. o que diriam os outros, se o encontrassem ferido de saudade ou tão injusta condição. era melhor que empedernisse verdadeiramente, muito masculino, um corpo bruto, por mais belo e claro que parecesse, preparado para abrir caminho na ferocidade de um país alheio (p. 47 - grifos nossos).

O ucraniano almeja transformar-se em metal para resistir ao peso do trabalho e da responsabilidade que assume, para tentar sobreviver ao novo mundo que habita.

\footnotetext{
2 A partir deste ponto, nas citações de o apocalipse dos trabalhadores, serão referidos somente o número de página.
} 
A imagem da máquina, do metal, do mineral é eficiente para isso, visto que "Se no mundo dos símbolos a resistência é humana, no mundo da energia a resistência é material" (2013b, p. 16-17). A "lógica" de Andriy parece alinhar-se ao que Bachelard explicita como a dialética da dureza, na qual há um jogo entre a dureza do que ataca e do que é atacado, e com uma psicologia social do contra: "Sob muitos aspectos, pode-se mesmo definir o caráter como um sistema de defesa do indivíduo contra a sociedade, como um processo de oposição a uma sociedade" (2013b, p.23). O elemento telúrico relacionado à vontade, por seu caráter de dureza, transforma-se em obstáculo a ser vencido, a ser dominado pelo homem - essa característica, porém, não deve desanimar, e sim estimular ao trabalho, à ação, à atividade.

Nesse movimento de aplacar a matéria dura, sem um resquício de água que poderia amolecê-lo, transformá-lo em massa moldável, o ucraniano empreende seu processo de metalização, buscando "secar todos os sentimentos", como o narrador explicita. Para um mundo duro, ele assume uma postura dura, com um semblante carregado e "os lábios incapazes de relaxarem, muito longe de saberem sorrir" (p.93). Ele o faz porque algo ou alguém "torna-se duro para durar. Só pode ficar duro concentrando-se em si, maltratando seus próprios ímpetos" (BACHELARD, 2013b, p. 53).

Além disso, também é possível pensar na identificação de Andriy com a terra em seu aspecto duro, voluntarioso, a partir da sua condição de estrangeiro. Como falamos anteriormente, cada elemento apresenta mais de uma valorização e, para a terra, além da relacionada à vontade, há igualmente aquela identificada com o repouso. Nessa segunda forma de encarar a matéria terrestre, surgem as imagens da casa e da terra natal: sonhando e devaneando com elas, o homem pode serenar, voltar ao seu centro, à sua origem, ao seu passado; pode deixar um pouco de lado o trabalho pesado e descansar.

Andriy está muito distante do país onde nasceu e onde ainda vivem seus progenitores - e essa distância é espacial, geográfica, potencializada pela falta de dinheiro para viajar e pela falta de perspectivas, pelo trabalho com um salário escasso. Assim, fica claro que, para o ucraniano, seria praticamente impossível o relacionamento com o elemento terrestre que leva ao repouso - a distância da sua terra mãe não lhe permite tal aproximação e esse distanciamento quase total leva-o ao outro extremo: a vontade e a dureza excessivas, culminando no anseio de transformar a si mesmo em máquina, tendo em vista a necessidade de um corpo bruto para "abrir caminho na ferocidade de um país alheio" (p.47).

Também a masculinidade do personagem, ressaltada no longo trecho citado anteriormente, fica explicada pela negação da terra como repouso. Não é apenas à pátria que a terra que chama ao descanso se associa: também surge a conexão com a maternidade, como se o território onde se nasce fosse um grande colo materno. De acordo com Durand, "essa crença na divina maternidade da terra é certamente uma das mais antigas; de qualquer modo, uma vez consolidada pelos mitos agrários, é uma das mais estáveis. [...] O sentimento patriótico (deve-se dizer matriótico) seria apenas a intuição subjetiva deste isomorfismo matriarcal e telúrico" (DURAND, 2002, p.231). Assim, por estar afastado de suas duas mães, a terra natal e a progenitora, para Andriy, é necessário identificar-se com o masculino, com o trabalho, com a força, com a resistência - tudo isso para não sentir, para não sofrer. Afinal, ele precisa enfrentar o que Julia Kristeva aponta em Estrangeiros para nós mesmos:

Inimigo a ser abatido nos grupos humanos mais selvagens, o estrangeiro, na esfera das concepções religiosas e morais, torna-se um homem diferente que, sob a condição de aderir a elas, pode ser comparado à aliança dos "sábios", dos "justos" ou dos "naturais". [...] a violência do problema hoje colocado pelo estrangeiro provém, sem dúvida, das crises das concepções religiosas e morais. É causada, sobretudo, pelo fato de que a absorção do estranho proposta por nossas sociedades revela-se inaceitável para o indivíduo moderno, defensor de sua diferença, não somente nacional e ética, mas essencialmente subjetiva, irredutível (KRISTEVA, 1994, p. 10).

Com o intuito de se transformar em máquina e, assim, de aniquilar, de certa forma, sua própria subjetividade para poder resistir e produzir, Andriy elimina primeiramente o divertimento, o prazer: "para ser uma máquina feliz, sabia-o bem o andriy, havia que manter-se cuidado e, por isso, ele acabara substancialmente com as saídas e as cervejas" (p.54), apesar de o amigo russo sugerir ao ucraniano que bebesse muito, no começo: "é importante perder a lucidez para não existir qualquer necessidade de ser entendido" (Idem). Contudo, o metal, como coloca Bachelard (2013b), é a concretização de uma recusa; se o personagem deseja transformar-se em máquina, ele deve, portanto, assumi-la como parte predominante da sua personalidade, começando por colocar um fim aos pequenos prazeres e subversões do cotidiano.

Como efeito de sua condição de estrangeiro, e talvez também de seu processo de metalização, o ucraniano tem dificuldade de expressar seus medos e sofrimento para Quitéria, com quem passa a sair regularmente. No entanto, ele está, em um primeiro momento, irredutível em relação à sua postura para encarar a vida: "o andriy parou, viu-se como um competente administrador de suas penas, pondo-lhes fim, uma a uma, com força de ferro" (p. 54-55 - grifo nosso). Mesmo que ele mantenha um contato frequente com a mulher, a relação dos dois, primeiramente, 
assim como o próprio Andriy, funciona maquinalmente, sem uma verdeira troca subjetiva profunda. Ele faz tudo isso porque precisa produzir, como trabalhador imigrante, o máximo possível, e a maneira efetiva de realizar isso é tornando-se máquina, metal. Como Kristeva destaca, o trabalho é uma das marcas do estrangeiro:

O imigrante, este não está ali para perder o seu tempo. Batalhador, audaz ou espertalhão, segundo as suas capacidades e circunstâncias, ele amealha todos os trabalhos e esforça-se por se sobressair nos mais difíceis. [...] o estrangeiro investe em si mesmo e se gasta. Se é verdade que fazendo isso tem em vista, como todo mundo, o lucro e a poupança futura para os seus, a sua economia passa (para atingir esse objetivo e mais do que nos outros) por uma prodigalidade de energia e de meios (KRISTEVA, 1994, p. 26).

Após as relações sexuais com Quitéria - algumas vezes suspensas pela angústia de Andriy -, o jovem sai imediatamente, recusa-se a passar a noite com ela, corroborando a superficialidade a unir o ucraniano à portuguesa:

haveria de ter a quitéria as vezes que quisesse, mas nunca permitir que isso o demovesse da progressiva metalização do corpo. via-se como platinado, robótico, uma força incrível e os sentidos alerta como seria impossível para uma cabeça só orgânica. nem por um momento julgou estar interessado na mulher além do sexo (p. 72-73).

O seu corpo necessita da mulher, como toda a máquina requer "abastecimento" (p. 64), mas ele recusa-se a estabelecer uma conexão para além disso - ele tenta o máximo que pode agir de maneira extremamente fria e impessoal, a fim de não criar uma ligação que pudesse estragar seu desenvolvimento em metal, essa substância igualmente fria, hostil, angulosa (BACHELARD, 2013b). Ele precisou deixar seu país de origem e seus progenitores, pois, na Ucrânia, a fome era uma realidade tão intensa e próxima, que "sentava-se todos os dias à mesa da ekaterina e do sasha" (p. 65), seus pais; ele foi obrigado a se afastar de sua zona de conforto e aventurar-se por uma terra completamente desconhecida com o desejo de enviar dinheiro para casa, e nada poderia desviá-lo de seu objetivo.

Dessa forma, Andriy deveria sempre conservar-se "incrivelmente eficiente no papel de quem não amava a quitéria e se portaria como uma máquina de trabalho a caminho da felicidade e mais nada" (p.50), sob a pena de sucumbir de tristeza pela falta dos pais e pela vida difícil e sem perspectivas, caso se permitisse ter sentimentos humanos, situação essa que poderia comprometer sua produtividade. O jovem ainda necessita conservar a frieza, característica própria do metal (BACHELARD, 2013b), não só em seu trato com Quitéria, mas inclusive em seu corpo, a fim de melhor se identificar com tal elemento: "o corpo nu dele parecia esfriar mais ainda o quarto, como se a pele descoberta fosse indutora de todo o frio da casa" (p.43). Como já se afastou da mãe e da terra natal, ele igualmente não pode criar vínculos com outras mulheres que lhe convidem ao repouso que a matéria terrestre também pode oferecer.

A indiferença a qual se impõe com seu processo de autometalização não deixa de ser também um componente de sua condição de imigrante em Portugal: "A indiferença é a carapaça do estrangeiro: insensível, distante, no fundo ele parece fora do alcance das agressões que, contudo, sente com a vulnerabilidade de uma medusa" (KRISTEVA, 1994, p.15). Outro aspecto que contribui para o descaso de Andriy em relação à Quitéria e aos demais portugueses e para o seu isolamento é o da língua diferente, intrínseco ao seu estatuto de imigrado. Sobre esse aspecto da condição de estrangeiro, Kristeva acredita que

entre duas línguas, seu elemento é o silêncio. [...] Encurralado nesse mutismo poliforme, o estrangeiro talvez tente, em vez de dizer, fazer: fazer a faxina, jogar tênis, futebol, velejar, costurar, cavalgar, correr, fazer filhos... sei lá mais o quê. Mas isso continua sendo um desperdício, um desgaste, além de propagar ainda mais o silêncio. Quem o escuta? No máximo, toleram você. Aliás, você quer realmente falar? (2004, p. 23).

$\mathrm{O}$ fato de ele falar um idioma muito distinto do português impossibilita sua compreensão do que as pessoas ao seu redor pensam e falam, assim como a compreensão das pessoas em relação ao que vai na mente dele. Quitéria, por exemplo, acredita que o jovem não é muito inteligente, quase tonto, como ela o qualifica, até que percebe que talvez a culpa da sua percepção de Andriy como alguém a quem falte perspicácia seja a barreira da língua: "as poucas palavras e as frases tão dificilmente construídas mostraram-lhe que ele estaria como um peixe fora de água, ali tão reduzido à sobrevivência, apenas um animal a precisar de respirar" (p. 44). Para não se importar por não se encontrar em seu elemento, em seu país de origem, e por não viver, mas apenas sobreviver, ele prefere transformar-se em metal, em máquina, em um objeto inanimado, silencioso.

Ainda analisando a relação de Andriy com Quitéria, é interessante observar a discrepância entre as visões dos dois personagens no que diz respeito ao sucesso ou ao insucesso do jovem em sua autometalização. Para o ucraniano, era bastante clara a aproximação cada vez maior de seu corpo a uma máquina, como quando deixa a mulher sem se virar para trás, em uma atitude pensada de 
desprezo, de altivez, de superioridade. Nesse momento, ele julga-se "incrivelmente eficiente no papel de quem não amava a quitéria e se portaria como uma máquina de trabalho a caminho da felicidade e mais nada" (p.50 grifo nosso). A portuguesa, por sua vez, enxerga-o como um "miúdo" (p. 49) - claro que o termo refere-se também à juventude de Andriy, que tem 23 anos, enquanto Quitéria já é uma mulher em seus 40 anos. Porém, o vocábulo igualmente aponta para a fragilidade do homem, sentida por sua amante através de seu disfarce de metal duro e resistente. Ela procura colocar-se no lugar do estrangeiro:

pensou, se me pusesse a milhares de quilómetros de casa, a carregar pedras o dia todo e a minha mãe adoecesse, se a minha mãe fosse importante para mim, porque não o diria ou, na verdade, porque não perderia por uma vez a vontade de ter sexo com alguém (p.49).

Assim, por maior que seja o esforço de Andriy no sentido da desumanização, Quitéria, desde o início da relação entre os dois, percebe sua verdadeira humanidade - e isso representará o fator de mudança e reversão da metalização do homem, como veremos mais adiante.

Contudo, por enquanto, o processo de transformação em máquina se intensifica ainda mais, na medida em que o jovem passa a não mais receber notícias dos pais, e, concomitante a isso, passa a ver o "homem de ouro":

o homem de ouro vinha pelo andriy, porque ninguém percebia aquilo, porque era só o que a sua cabeça inventava. o rapaz olhava para diante e era como um filme projectado em tela, vindo dos seus olhos para as traves tombadas no chão, de onde o homem de ouro ficava a observá-lo, quieto, sem ensejo de conversa, apenas a exposição do brilho intenso da riqueza, da metalizaçâo do corpo com o mais nobre dos metais (p. 83).

O homem de ouro era o mealheiro que ficou no Ucrânia, que a família mantinha desde a infância de Andriy. Ele representa a coleta das economias, a possibilidade de um futuro para o jovem. Sobre as aparições do mealheiro, "o andriy sabia que o homem de ouro era apenas uma ilusão da sua cabeça, uma projeção da sua própria força de vontade" (p. 161). Por isso, o homem de ouro era um estímulo ao processo ao qual o ucraniano havia se submetido:

e os pais, estranhamente, emudeceram para sempre, ficando o filho sozinho no país das flores, forçando o coração a ganhar foles, deitar fumo, substituir o sangue por óleo, verter para os outros órgãos como dentro de um motor, tendo radiador, ventoinhas, estruturas inoxidáveis no caminho do esqueleto, propulsores, tubos comunicantes, roldanas, anilhas e parafusos, mecanismos dentados como a ferrarem-se impiedosamente uns nos outros e para sempre, visores perfeitos para o futuro coberto de ouro, já muito mais fácil de existir (p. 83-84).

Todo esse processo de metalização de Andriy é a forma que ele encontra para enfrentar, em sua condição de estrangeiro, o mundo onde ele vive, regido pelo capitalismo tardio, sob a tutoria do homem de ouro, que o estimula, que o questiona em momentos de dúvida. Em sua mente, ao trabalhar exaustivamente - e é isso que o capataz exige dele e dos outros com quem o jovem mora junto -, ele produzirá o suficiente para se manter e ajudar a família na Ucrânia, e ainda com a falsa ideia de que, dessa maneira, conseguirá esquecer o seu próprio sofrimento, em um processo de indiferença em relação a si mesmo e aos outros.

Jonhathan Crary, em seu ensaio 24/7 - Capitalismo tardio e os fins do sono, afirma que esse tempo em que a produtividade e, obviamente, o consumo precisam funcionar 24 horas por dia, 7 dias por semana, "é um tempo de indiferença” (CRARY, 2014, p. 19). Para ele, a fragilidade humana passa a ser considerada cada vez mais anômala e a ideia de trabalhar ilimitadamente, mais normal. Dessa maneira, o trabalhador "Alinha-se com o inanimado, com o inerte ou com o que não envelhece" (CRARY, 2014, p.19). Andriy cede ao que o sistema exige, espera ou, no mínimo, proporciona: ele quer virar máquina, cortando relações emocionais, trabalhando exaustivamente, para produzir o máximo. Ele quer ser uma máquina, e isso é uma possibilidade coerente com a realidade, visto que "um ambiente $24 / 7$ parece um mundo social, mas é na verdade um modelo não social de desempenho maquínico e uma interrupção da vida que não revela o custo humano exigido para sustentar sua eficácia" (ibidem - grifo nosso).

Imigrante e totalmente sob o jugo de um sistema econômico que pode exauri-lo completamente por meio do trabalho, a atitude de Andriy corrobora com a ideia de que

Em face de um mundo real, pode-se descobrir em si mesmo o ser da inquietação. Somos então jogados no mundo, entregues à inumanidade do mundo, à negatividade do mundo, o mundo é então o nada do humano. As exigências de nossa função real obrigam-nos a adaptar-nos à realidade, a construir-nos como uma realidade, a fabricar obras que são realidades. Mas o devaneio, em sua própria essência, não nos liberta da função do real? Se o considerarmos em sua simplicidade, veremos que ele é o testemunho de uma função do irreal, função normal função útil, que protege o psiquismo humano, à margem de todas as brutalidades de um não-eu hostil, de um não-eu estranho (BACHELARD, 2009, p. 13 - grifos do autor). 
Nesse contexto, coerentemente, Andriy quer ser máquina metálica, já que

o metal é a própria substância da frieza [...]. A hostilidade do metal é assim o seu primeiro valor imaginário. Duro, frio, pesado, anguloso, ele tem tudo para ser ofensivo, psicologicamente ofensivo. [...] O metal é um protesto material. Será necessária toda a energia dos devaneios da provocação para 'domá-lo'. De qualquer modo, sua frieza, sua indiferença impõem certo respeito por esse 'filho primogênito' dos produtos da terra (BACHELARD, 2013b, p. 191).

Em certa medida, o ucraniano atinge seu objetivo, e até sexualmente Quitéria percebe isso: ele torna-se muito mais viril, apesar de sua beleza, primeiramente, delicada; ela "submetia-se, tão óbvia, ao mecânico amor dele" (p.94). No entanto, apesar de que "o sexo poderia resultar melhor, mais agreste como elementar e tão animal" (p.98), a situação torna-se insustentável para Andriy. Sua agonia interna, a preocupação com o destino dos pais e o envolvimento emocional com Quitéria cada vez maior. Com tudo isso fugindo ao seu controle, o processo de metalização mostra sinais de definhamento: "a máquina avariou-se gravemente. rigorosamente, começou a estrebuchar como por falta de combustível, o barulho gutural e intenso, depois de um esticão mais longo e muito breve até ficar imóvel" (p.98).

Andriy chega ao extremo:

a quitéria retirou as suas pernas de baixo da máquina e aproximou o olhar da cabeça. levou, acto contínuo, a mão ao rosto do rapaz. estava desligado. os olhos abertos sem expressão, completamente ausentes. o andriy desligara-se numa agonia comovedora (p. 98 - grifos nossos).

Esse limite último da indiferença, a ausência, é o que o capitalismo tardio vai proporcionar, visto que o sistema " $24 / 7$ mina paulatinamente as distinções entre dia e noite, entre claro e escuro, entre ação e repouso. É uma zona da insensibilidade, da amnésia, de tudo que impede a possibilidade de experiência" (CRARY, 2014, p. 26). Resistentemente, o jovem expõe suas fragilidades à Quitéria:

ele tinha medo, porque por ela perderia a possibilidade de ser feliz e voltaria a sua condição humana para aceitar que não suportava a ausência de notícias dos pais ou a fixação mais complexa por um sentimento que, genericamente, se chamaria amor (p.98).

$\mathrm{Na}$ medida em que o processo de endurecimento perde força, os laços com Quitéria começam a aumentar, com ele cedendo ao ponto de fazer uma refeição com ela.
Kristeva (1994) observa como a condição do estrangeiro pode ter nuanças atenuadas por aquilo que ela considera um encontro de alteridades, e

O encontro em geral começa com uma festa do paladar: pão, sal e vinho. Uma refeição, uma comunhão nutritiva. Um confessa-se bebê faminto, o outro acolhe essa criança ávida: num instante, eles se fundem no rito da hospitalidade (1994, p. 19).

Ele começa a prezar e a valorizar a aproximação entre os dois e igualmente a se conformar à sua humanidade, o que fica claro quando o narrador afirma que o jovem estava "apenas cansado e ocupado em aceitar-se como um complexo orgânico e, se calhar já não infelizmente, nada maquinal" (p. 102). Mais tarde, Andriy cede ainda mais, e passa a dormir com ela, o que não fazia antes. Isso, que poderia ser um detalhe banal, revela um movimento contrário ao do sistema 24/7, ao sistema da máquina e de relações não sociais. Crary lembra que várias ideias essenciais à organização social - algo humano, e não maquinal - se organizam ao redor do fator "sono", do dormir,

na reciprocidade entre vulnerabilidade e confiança, entre exposição e proteção. É crucial a dependência da guarda de outros para a despreocupação revigorante do sono, para um intervalo periódico no qual se está livre de temores, e para um esquecimento temporário do 'mal' (CRARY, 2014, p. 38 - grifo do autor).

Andriy agora tem alguém para guardar seu sono, e pode descansar momentaneamente de suas preocupações, não precisando submeter-se à vigília constante das máquinas. Reestabelecendo seus vínculos sociais por meio da relação com Quitéria, ele permite que ela vigie seu sono. Além disso,

o sono é uma das poucas experiências restantes na qual, saibamos ou não, nos abandonamos ao cuidado dos outros. Por solitário ou privado que o sono pareça, ainda não foi separado da trama e do apoio mútuo e de confiança, por mais danificados que esses vínculos estejam (CRARY, 2014, p. 134).

Quitéria ainda é para Andriy o elemento terra em seu aspecto de repouso por ser mulher e por guardar o sono dele, permitindo seu descanso e abandono totais, mas também por representar a chance de o jovem retornar à sua terra natal e descobrir como estão seus pais, que não enviam mais cartas e notícias: ela decide comprar, com suas economias, passagens para os dois visitarem a Ucrânia. A partir da mulher é que o ucraniano reconcilia-se com sua humanidade, pois ela lhe possibilita a reaproximação com sua origem, fonte de energia e de vitalidade - seus pais e sua pátria. 
O poder onírico da matéria está no fato de que "Se as coisas colocam em ordem nossas ideias, as matérias elementares colocam em ordem nossos sonhos. As matérias elementares recebem e conservam e exaltam os nossos sonhos" (BACHELARD, 2013a, p. 140). A metalização, o transformar-se em máquina, foi a tentativa de Andriy em organizar seus impulsos de enfrentar o mundo resistente, usando "força de ferro" (p. 55), agindo, "calado de chumbo" (p.47) e vendo-se "como platinado, robótico, uma força incrível" (p.72). Por um lado, transformar-se máquina parece ser uma forma de ceder ao sistema do capitalismo tardio; por outro, é uma forma de tentar sobreviver a ele. Seu devaneio não é cósmico, o jovem não quer durar muito tempo. Ele quer é resistir e, para isso, adota uma estratégia devaneante, visto que

Não é possível harmonizar seres vivos reais com as demandas do capitalismo 24/7, mas existem inúmeros incentivos para suspender ou disfarçar ilusoriamente algumas das limitações humilhantes da experiência vivida, seja emocional ou biológica. Figurações do inerte ou do inanimado também operam como um escudo protetor ou intorpecente, que impede o reconhecimento do caráter dispensável da vida nos arranjos econômicos e institucionais contemporâneos (CRARY, 2014, p. 110).

Andriy incentivou-se, impôs-sê um processo de metalização. No entanto, ele falha. O objetivo de Andriy, na verdade, é antes um devaneio da vontade, do trabalho para enfrentar a dureza, e não uma mera insensibilidade maquinal. Porém, ele empreendeu o processo de maneira que seu esforço não se deu como o que Bachelard entende por "trabalho onírico". Esse modelo é discrepante ao sistema $24 / 7$ do capitalismo tardio, e por isso a empreitada não satisfez a integridade do seu ser, efetivamente. $\mathrm{O}$ processo de metalização a que o jovem submeteu-se foi, de certo modo, anti-onírico, já que "O trabalho, ao nos obrigar a essas lutas, oferece-nos uma espécie de psicanálise natural. Essa psicanálise leva seus poderes de liberação a todas as camadas do ser" (BACHELARD, 2013b, p.39). O trabalho onírico torna o ser humano plenamente humano, e não máquina.

\section{Referências}

BACHELARD, Gaston. A poética do devaneio. 3a. ed. São Paulo: Editora WMF Martins Fontes, 2009.

A água e os sonhos: ensaio sobre a imaginação da matéria. 2. ed. São Paulo: WMF Martins Fontes, 2013a.

- A terra e os devaneios da vontade: ensaio sobre a imaginação das forças. 4. ed. São Paulo: WMF Martins Fontes, 2013b.

A terra e os devaneios do repouso: ensaio sobre as imagens da intimidade. São Paulo: Martins Fontes, 1990.

CRARY, Johnathan. 24/7 - Capitalismo tardio e os fins do sono. São Paulo: Cosac Naify, 2014.

DURAND, Gilbert. As estruturas antropológicas do imaginário. São Paulo: Martins Fontes, 2002. A imaginação simbólica. Lisboa: Edições 70, 1993.

KRISTEVA, Julia. Estrangeiros para nós mesmos. Rio de Janeiro: Rocco, 1994.

MÃE, Valter Hugo. o apocalipse dos trabalhadores. São Paulo: Cosac Naify, 2013.

WUNENBURGER, Jean-Jacques. O imaginário. São Paulo: Edições Loyola, 2003.

Recebido: 24 de abril de 2016.

Aprovado: 02 de agosto de 2016.

Contato: brunomazolini@gmail.com luara.minuzzi@acad.pucrs.br 